\title{
Glycaemic status influences the nature and severity of coronary artery disease
}

\author{
C. Berry • S. Noble • J. C. Grégoire • R. Ibrahim • \\ S. Levesque • M.-A. Lavoie • P. L. L'Allier • J.-C. Tardif
}

Received: 9 June 2009 / Accepted: 4 December 2009 / Published online: 14 January 2010

(C) Springer-Verlag 2010

\begin{abstract}
Aims/hypothesis We sought to understand the relationships between glycaemic status and both severity and progression of coronary artery disease (CAD), the leading cause of death in diabetes.

Methods Baseline fasting blood glucose (FBG) and $\mathrm{HbA}_{1 \mathrm{c}}(\%)$ were measured in 426 patients with known or suspected stable $\mathrm{CAD}$, who underwent coronary artery intravascular ultrasound (IVUS) at baseline and after a mean follow-up period of 664 days (range 257 to 961). The patients were categorised as normoglycaemic $(n=226,53 \%)$, or as having impaired fasting glucose $(n=118,28 \%)$ or diabetes $(n=82,19 \%)$.

Results The maximum percentage coronary atheroma area at baseline was greater in diabetic patients $(73.33 \pm 8.86 \%)$ than in those with normoglycaemia $(69.08 \pm 10.43 \% ; p=0.001)$ and impaired fasting glucose $(69.32 \pm 9.59 \% ; p=0.0031)$. In averaged IVUS measurements of the 30 -mm target segment ( $n=332$ participants), change in percentage atheroma area during follow-up was also greater in the diabetes $(1.86 \pm$ $3.90 \%)$ than in other groups $(0.28 \pm 3.32 \%$ and $0.56 \pm 2.96 \%$, $p=0.0047$ global). FBG correlated with maximum percentage atheroma area at baseline $(r=0.17 ; p=0.0003)$. $\mathrm{HbA}_{1 \mathrm{c}}$ also correlated with maximum percentage atheroma area at baseline $(r=0.26 ; p=0.0001)$ and with change in maximum plaque area $(r=0.16 ; p=0.016)$. A similar pattern of results
\end{abstract}

C. Berry $\cdot$ S. Noble $\cdot$ J. C. Grégoire $\cdot$ R. Ibrahim $\cdot$ M.-A. Lavoie $\cdot$

P. L. L'Allier $\cdot$ J.-C. Tardif $(\bowtie)$

Montreal Heart Institute and Université de Montréal,

5000 Belanger Street,

Montreal, QC H1T 1C8, Canada

e-mail: jean-claude.tardif@icm-mhi.org

S. Levesque

Montreal Heart Institute Coordinating Center (MHICC),

Montreal, QC, Canada occurred with plaque volume. The relationships between diabetes or $\mathrm{HbA}_{1 \mathrm{c}}$ and both IVUS measurements of plaque burden and remodelling persisted after adjustment.

Conclusions/interpretation Fasting blood glucose, $\mathrm{HbA}_{1 \mathrm{c}}$ and the presence of diabetes are associated with the severity and progression of coronary atherosclerosis. These observations support the hypothesis that better glycaemic control may favourably influence CAD in patients with abnormal glucose tolerance or diabetes.

Keywords Atherosclerosis · Coronary artery disease . Diabetes · Glucose
Abbreviations
CAD Coronary artery disease
D Dimensional
FBG Fasting blood glucose
IFG Impaired fasting glucose
IVUS Intravascular ultrasound

\section{Introduction}

Despite the increasing global prevalence of glucose intolerance and diabetes, a disease where coronary artery disease (CAD) is the leading cause of death [1], the evolution of $\mathrm{CAD}$ in these conditions is incompletely understood. To date, quantitative studies of human coronary atherosclerosis in patients with diabetes have provided conflicting information [2-5]. Also, while individuals with impaired fasting glucose (IFG) tolerance have an increased cardiovascular risk [6], the severity and progression of coronary atherosclerosis in this group have not been compared with that in patients with and without diabetes. 
Coronary angiography is the standard clinical method for CAD assessment, but it only provides a silhouette image of the arterial lumen and thus fails to adequately quantify CAD severity [7]. Intravascular ultrasound (IVUS) provides a quantitative tomographic assessment of atheroma burden and its change over time, as well as of atheroma progression or regression; it is therefore a much more sensitive tool for CAD evaluation than angiography [8, 9]. IVUS also characterises coronary artery remodelling [10]. However, IVUS studies of glycaemic status and CAD have been limited by small sample size and lack of serial imaging $[2,11,12]$.

The purpose of this study was to define the features of CAD in patients with impaired glucose tolerance and in those with diabetes using retrospective analysis of patients who had undergone serial IVUS measurements as part of a clinical trial. We hypothesised that graded relationships would exist between glycaemic status and both coronary atheroma severity and remodelling at single time-points and during follow-up.

\section{Methods}

Patient population The patients in this study were drawn from the Avasimibe and progression of coronary lesions assessed by intravascular UltraSound (A-PLUS) trial, a multicentre placebo-controlled study of the acyl coenzyme A: cholesterol acyltransferase enzyme inhibitor, avasimibe [13]. In 25 centres in Canada, US, Europe, Australia and South Africa, 525 patients had a baseline IVUS assessment $[13,14]$. Of these, 426 also had an evaluable repeat IVUS examination with glycaemic data [14]. These patients underwent clinically indicated coronary angiography at baseline for suspected or proven CAD. To facilitate the IVUS examination, the target coronary artery for IVUS needed to have a 20 to $50 \%$ diameter stenosis in a coronary artery $\geq 2.5 \mathrm{~mm}$ in diameter by visual angiographic assessment. Patients undergoing percutaneous coronary intervention of a non-IVUS target artery could be included. The protocol was approved by the Institutional Review Boards of all participating sites [14] and all patients gave written informed consent.

Patients were randomly assigned to one of three doses of avasimibe or to placebo [14]. Patients with normal fasting blood glucose (FBG), IFG and diabetes were distributed equally among the treatment groups $(p=0.62)$. The average duration of follow-up was 664 days (range 257 to 961). None of the three doses of avasimibe had a significant effect upon the IVUS endpoint measures of the study [14].

Definitions of IFG and diabetes Fasting blood glucose, $\mathrm{HbA}_{1 \mathrm{c}}$, body weight, BMI and diabetes treatment at baseline were recorded. The only exclusion criterion with respect to diabetes or its treatment was patients with uncontrolled diabetes defined as $\mathrm{HbA}_{1 \mathrm{c}}>10 \%$. Glucose, $\mathrm{HbA}_{1 \mathrm{c}}$ and other blood chemistry measurements were done by a central core laboratory using standard techniques. Blood tests were performed after an overnight fast.

Diabetes was considered present at baseline if the patient had a history of diabetes (with or without treatment) or baseline $\mathrm{FBG} \geq 7.0 \mathrm{mmol} / \mathrm{l}(126 \mathrm{mg} / \mathrm{dl})$ [15]. IFG was defined as $\mathrm{FBG} \geq 5.6 \mathrm{mmol} / \mathrm{l}$ but $<7.0 \mathrm{mmol} / 1$ [15]. $\mathrm{FBG}<$ $5.6 \mathrm{mmol} / \mathrm{l}$ was considered normal.

IVUS image acquisition and analysis The IVUS method employed has been described in detail previously [13]. In brief, single-vessel coronary IVUS studies were performed at baseline and follow-up using $30 \mathrm{MHz}$ IVUS catheters (Boston Scientific, Natick, MA, USA). The IVUS catheter was advanced distally at least $40 \mathrm{~mm}$ beyond the coronary artery ostium to a recognisable landmark (arterial branch). The transducer was then pulled back automatically at a speed of $0.5 \mathrm{~mm} / \mathrm{s}$ up to the guiding catheter, using a motorised device. A second pullback was then performed in the same coronary artery using the same guidelines to ensure high-quality imaging [16].

All IVUS examinations were analysed at the Montreal Heart Institute IVUS Core Laboratory by experienced technicians supervised by a cardiologist according to published standards $[9,17]$. The lumen and external elastic membrane borders were manually traced on one of every four digitised cross-sections with a custom-developed system (INDEC BioSystems, Mt View, CA, USA). Contours were interpolated for all the digitised cross-sections between the ones manually drawn. A total of 900 crosssections were analysed in the $30-\mathrm{mm}$ coronary artery segment of interest at baseline and follow-up.

IVUS endpoints and definitions The two-dimensional (D) outcome measures at baseline and follow-up consisted of the largest plaque area, the minimum lumen area and the total vessel area. Percentage atheroma area (cross-sectional area narrowing) was also calculated, equal to the largest plaque area divided by the total vessel area multiplied by 100. Percentage atheroma area therefore represents the fraction of total vessel area occupied by plaque [9]. In addition, mean plaque area, mean lumen area and mean vessel area were calculated from serial measurements obtained within the same coronary artery. Averaged measurements from these cross-sections were available in 332 participants.

The 3-D IVUS endpoints were: (1) plaque volume, lumen volume, total vessel volume and percentage atheroma volume at baseline and follow-up; and (2) their change over time in matched $30 \mathrm{~mm}$ target coronary artery segments (900 images traced at baseline and follow-up). 
Percentage atheroma volume was calculated by dividing plaque volume by total vessel volume and then multiplying by 100 . Plaque, lumen and total vessel volumes were computed for the entire length of the analysed segments by multiplying the corresponding areas of each of the crosssections by the distance between the neighbouring slices and then adding all the products. The intraclass correlation coefficients for inter-observer variability of measurement of plaque and vessel volumes in our laboratory are 0.98 and 0.99 [18]. 3-D measurements were available in 419 participants. The nominal changes in 2-D and 3-D variables were calculated by subtracting baseline data from follow-up measurements. Vascular remodelling, defined as the change in total vessel dimensions over time, was characterised by analyses of 2-D and 3-D measurements [9, 17].

Statistical analyses Continuous data are presented as mean \pm SD or difference in mean \pm SEM. Correlations were performed using Pearson's tests. One-way ANOVA, Kruskal-Wallis non-parametric test and $\chi^{2}$ test were conducted to analyse baseline data and evaluate associations between glycaemic status and continuous 2-D and 3-D IVUS variables. Homogeneity of the correlation coefficients was tested by a $z$ statistic based on Fisher's $z$ transformation of correlation coefficients, in order to assess the influence of baseline percentage atheroma area on the relationships between plaque area and lumen and vessel areas. Multivariate backward linear regressions were performed to assess whether glycaemic status, $\mathrm{FBG}$ and $\mathrm{HbA}_{1 \mathrm{c}}$ were independent predictors of IVUS measurements. The variables included in these models were age, sex, systolic and diastolic blood pressure, smoking, BMI, statin use and hypertensive medication at baseline (beta blockers, ACE inhibitors, angiotensin receptor blockers or calcium channel blockers). Lipid measurements and C-reactive protein were included in the models with FBG and $\mathrm{HbA}_{1 \mathrm{c}}$. Only variables with $p<0.2$ in univariate analysis were considered in the multivariate analyses. A two-sided probability level of $p<0.05$ was taken as significant. All analyses were done with SAS (version 9.1; SAS Institute, Cary, NC, USA).

\section{Results}

Of the 426 patients included in the study, $226(53 \%)$ had normal FBG, 118 (28\%) had IFG and 82 (19\%) had diabetes. Of these, 332 (175 [53\%] with normal FBG, 90 [27\%] with IFG and 67 [20\%] with diabetes) had paired measurements for mean coronary dimensions in the analysed segment. The baseline features of the three groups are listed in Table 1. As expected, BMI, systolic blood pressure and $\mathrm{HbA}_{1 \mathrm{c}}$ levels increased from the normal to the IFG group, and from the IFG to the diabetes group.
Coronary atheroma burden and progression As shown in Table 2 for the 2-D IVUS data, the minimum lumen area in the $30-\mathrm{mm}$ target coronary artery segment was smaller at baseline in participants with diabetes $(p=0.019)$, while maximum percentage atheroma area at baseline $(p=0.0031)$ and at follow-up $(p=0.0096)$ was greater than in normoglycaemic and IFG participants. In a multivariate model including age, sex, systolic and diastolic blood pressure, statin use and hypertensive medication at baseline, diabetes $(p=0.0044)$ and hypertensive medication $(p=0.029)$ were the only predictors of maximum percentage atheroma area at baseline. Minimum lumen area at baseline, an index of remodelling, correlated with diabetes $(p=0.019)$, hypertensive medication $(p=0.037)$ and female sex $(p=0.0071)$ in the multivariate model.

For the averaged 2-D IVUS data, mean percentage atheroma area was greater at baseline $(p=0.023)$ and at follow-up $(p=0.0008)$ in participants with diabetes than in the other two groups. The change over time in mean percentage atheroma area was also greater in diabetic participants than in normoglycaemic $(p=0.0012)$ and IFG $(p=0.017)$ participants.

Similarly, for the 3-D IVUS data, percentage atheroma volume was greater at baseline $(p=0.0047)$ and at followup $(p=0.0005)$ in participants with diabetes than in normoglycaemic and IFG participants. For each of the aforementioned IVUS measurements, the differences in the normal and IFG groups were not statistically significantly different.

Differences in remodelling patterns according to glycaemic status and atheroma severity Change in mean plaque area correlated with change in mean lumen area by 2 -D IVUS in normoglycaemic $(r=0.34, p<0.0001)$ and IFG participants $(r=0.57, p<0.0001)$, but not in diabetic participants $(p=0.72)$. The correlation between change in mean plaque area and change in mean lumen area was influenced by the severity of percentage atheroma area at baseline, this influence being subject to a threshold effect, which differed according to glycaemic status: thus the mean percentage atheroma area threshold was $30 \%$ in the normoglycaemic group $(p=0.0011), 40 \%$ in the IFG group $(p=0.038)$ and $50 \%$ in diabetes $(p=0.0001)$. The positive correlation between change in mean plaque area and change in mean vessel area also differed in all patients when categorised according to percentage atheroma area severity at baseline ( $\leq 50 \%$ vs $>50 \%, p=0.015)$, particularly in diabetic patients.

By 3-D IVUS, lumen volume at follow-up tended to be smaller in diabetic patients $\left(216.73 \pm 89.57 \mathrm{~mm}^{3}\right)$ than in IFG $\left(244.84 \pm 90.84 \mathrm{~mm}^{3}\right)$ and normoglycaemic $(235.73 \pm$ $\left.79.30 \mathrm{~mm}^{3}\right)$ participants $(p=0.07)$. Change in per cent atheroma volume tended to correlate with change in total 
Table 1 Baseline characteristics of the 426 participants according to glycaemic status

\begin{tabular}{|c|c|c|c|c|c|c|c|c|}
\hline \multirow[t]{2}{*}{ Variables } & \multirow[t]{2}{*}{ All } & \multirow[t]{2}{*}{ NG } & \multirow[t]{2}{*}{ IFG } & \multirow[t]{2}{*}{ Diabetes } & \multirow[t]{2}{*}{$p$ value } & \multicolumn{3}{|l|}{$p$ value } \\
\hline & & & & & & NG vs IFG & $\begin{array}{l}\text { Diabetes } \\
\text { vs NG }\end{array}$ & $\begin{array}{l}\text { Diabetes } \\
\text { vs IFG }\end{array}$ \\
\hline$n(\%)$ & 426 & $226(53)$ & $118(28)$ & $82(19)$ & & & & \\
\hline Men $(\%)$ & $344(81)$ & $174(77)$ & $105(89)$ & $65(79)$ & 0.026 & 0.0070 & 0.67 & 0.058 \\
\hline Age (years) & $58 \pm 10$ & $57 \pm 10$ & $58 \pm 9$ & $60 \pm 10$ & 0.14 & & & \\
\hline BMI $\left(\mathrm{kg} / \mathrm{m}^{2}\right)$ & $28.5 \pm 3.9$ & $27.9 \pm 4.0$ & $28.9 \pm 3.3$ & $29.8 \pm 4.3$ & 0.0004 & 0.031 & 0.0001 & 0.077 \\
\hline Current smoker, $n(\%)$ & 79 (19) & $45(20)$ & $20(17)$ & $14(17)$ & 0.74 & & & \\
\hline Systolic BP (mmHg) & $127 \pm 18$ & $125 \pm 17$ & $128 \pm 18$ & $133 \pm 21$ & 0.0015 & 0.17 & 0.0003 & 0.032 \\
\hline Diastolic BP (mmHg) & $75 \pm 10$ & $76 \pm 11$ & $75 \pm 10$ & $75 \pm 10$ & 0.98 & & & \\
\hline FBG (mmol/l) & $5.7 \pm 1.6$ & $4.9 \pm 0.5$ & $5.9 \pm 0.3$ & $7.7 \pm 2.4$ & $<0.0001$ & $<0.0001$ & $<0.0001$ & $<0.0001$ \\
\hline $\mathrm{HbA}_{1 \mathrm{c}}(\%)^{\mathrm{a}}$ & $6.0 \pm 1.0$ & $5.4 \pm 0.3$ & $5.6 \pm 0.3$ & $7.0 \pm 1.1$ & $<0.0001$ & 0.0002 & $<0.0001$ & $<0.0001$ \\
\hline C-reactive protein $\left(\mathrm{mg} / \mathrm{l}^{\mathrm{b}}\right.$ & $3.4 \pm 7.0$ & $3.5 \pm 5.6$ & $3.3 \pm 10.2$ & $3.3 \pm 3.7$ & 0.18 & & & \\
\hline Total cholesterol $(\mathrm{mmol} / \mathrm{l})$ & $4.3 \pm 0.7$ & $4.3 \pm 0.7$ & $4.3 \pm 0.7$ & $4.3 \pm 0.6$ & 0.50 & & & \\
\hline LDL-cholesterol (mmol/l) & $2.4 \pm 0.5$ & $2.4 \pm 0.5$ & $2.4 \pm 0.5$ & $2.4 \pm 0.5$ & 0.75 & & & \\
\hline HDL-cholesterol (mmol/1) & $1.1 \pm 0.3$ & $1.2 \pm 0.3$ & $1.1 \pm 0.3$ & $1.1 \pm 0.3$ & 0.20 & & & \\
\hline VLDL $(\mathrm{mmol} / \mathrm{l})^{\mathrm{b}}$ & $0.9 \pm 0.4$ & $0.8 \pm 0.4$ & $0.9 \pm 0.5$ & $0.9 \pm 0.3$ & 0.021 & 0.12 & 0.0072 & 0.28 \\
\hline Triacylglycerol (mmol/l) & $1.6 \pm 0.8$ & $1.6 \pm 0.8$ & $1.7 \pm 0.9$ & $1.7 \pm 0.7$ & 0.074 & & & \\
\hline \multicolumn{9}{|l|}{ Medication, $n(\%)$} \\
\hline ACE inhibitor & $155(36)$ & $69(31)$ & $43(36)$ & $43(52)$ & 0.0020 & 0.27 & 0.0004 & 0.025 \\
\hline Angiotensin receptor blocker & $33(8)$ & $15(7)$ & $9(8)$ & $9(11)$ & 0.45 & & & \\
\hline Beta blocker & $283(66)$ & $154(68)$ & $73(62)$ & $56(68)$ & 0.47 & & & \\
\hline Calcium antagonist & $134(31)$ & $63(28)$ & $46(39)$ & $25(30)$ & 0.11 & & & \\
\hline Statin & 380 (89) & $203(90)$ & $108(92)$ & $69(84)$ & 0.23 & & & \\
\hline
\end{tabular}

Unless otherwise indicated, values are mean $\pm 1 \mathrm{SD}$.

${ }_{n}$ =224 participants; $\mathrm{HbA}_{1 \mathrm{c}}$ was available for 98 normoglycaemic, 54 prediabetic and 72 diabetic participants

${ }^{\mathrm{b}}$ Data were non-normally distributed and a non-parametric Kruskal-Wallis test was used for these variables

NG, normoglycaemia

vessel volume in diabetic participants $(r=-0.21, p=0.059)$, but not in IFG $(p=0.30)$ or normoglycaemic participants $(p=0.98)$.

Relationships between both $\mathrm{FBG}$ and $\mathrm{Hb} \mathrm{A}_{1 \mathrm{c}}$ and coronary atheroma severity Fasting blood glucose at baseline correlated with maximum percentage atheroma area at baseline $(r=0.17, p=0.0003)$ as shown in Table 3. FBG correlated negatively with minimum lumen area at baseline $(r=-0.14$, $p=0.0026)$ and at follow-up ( $r=-0.10, p=0.043)$. In averaged measurements, FBG also correlated with mean plaque area at follow-up $(r=0.12, p=0.03)$. A similar pattern of correlations occurred between FBG and percentage atheroma volume, both at baseline $(r=0.15, p=0.002)$ and follow-up ( $r=0.15, p=0.0016)$. FBG tended to correlate negatively with lumen volume at baseline $(r=-0.09$, $p=0.066)$ and at follow-up $(r=-0.09, p=0.083)$.

$\mathrm{HbA}_{1 \mathrm{c}}$ levels were available in 224 participants at baseline. $\mathrm{HbA}_{1 \mathrm{c}}$ ranged from 4.0 to $<6.0 \%$ in 150 participants $(67 \%)$, from 6.0 to $<7.0 \%$ in $41(18 \%)$ and from 7.0 to $<8.0 \%$ in $23(10 \%)$; in ten $(4 \%)$ patients, it was $\geq 8.0 \%$. The correlations with $\mathrm{HbA}_{1 \mathrm{c}}$ were roughly similar to those described above for $\mathrm{FBG}$. $\mathrm{HbA}_{1 \mathrm{c}}$ correlated positively with maximum percentage atheroma area at baseline $(r=0.26, p=0.0001)$ and at follow-up $(r=0.23$, $p=0.0006)$, and with the changes in plaque area $(r=0.16$, $p=0.016)$ and maximal vessel area $(r=0.20, p=0.0023)$. $\mathrm{HbA}_{1 \mathrm{c}}$ correlated negatively with minimum lumen area at baseline $(r=-0.19, p=0.0042)$. In averaged measurements, $\mathrm{HbA}_{1 \mathrm{c}}$ correlated with mean plaque area at follow-up ( $r=$ $0.15, p=0.040)$, and with the changes in mean plaque area $(r=0.22, p=0.0017)$ and mean percentage atheroma area $(r=0.15, p=0.042) . \mathrm{HbA}_{1 \mathrm{c}}$ also correlated with plaque volume at baseline and at follow-up, as shown in Table 3, as well as with the change over time in plaque volume $(r=$ $0.18, p=0.0055$ ).

To determine whether there might be a threshold for $\mathrm{HbA}_{1 \mathrm{c}}$, we examined percentage atheroma volume at baseline in quartiles of $\mathrm{HbA}_{1 \mathrm{c}}$. A significant correlation was seen $(p=0.016)$, with percentage atheroma volume being higher in the highest quartile, where $\mathrm{HbA}_{1 \mathrm{c}}$ was 
Table 2 Comparisons between IVUS data in patients with and without diabetes

\begin{tabular}{|c|c|c|c|c|c|c|c|c|}
\hline \multirow[t]{2}{*}{ Variables } & \multirow[t]{2}{*}{ All } & \multirow[t]{2}{*}{ NG } & \multirow[t]{2}{*}{ IFG } & \multirow[t]{2}{*}{ Diabetes } & \multicolumn{4}{|l|}{$p$ value } \\
\hline & & & & & Global & $\begin{array}{l}\text { NG } \\
\text { vs IFG }\end{array}$ & $\begin{array}{l}\text { Diabetes } \\
\text { vs NG }\end{array}$ & $\begin{array}{l}\text { Diabetes } \\
\text { vs IFG }\end{array}$ \\
\hline Per cent of total cohort & & 53 & 28 & 19 & & & & \\
\hline \multicolumn{9}{|l|}{ 2-D IVUS data } \\
\hline $\begin{array}{l}\text { Minimum lumen area at } \\
\text { baseline }\left(\mathrm{mm}^{2}\right)\end{array}$ & $4.55 \pm 2.17$ & $4.68 \pm 2.13$ & $4.71 \pm 2.28$ & $3.94 \pm 2.01$ & 0.019 & 0.90 & 0.0082 & 0.014 \\
\hline $\begin{array}{l}\text { Maximum \% atheroma area } \\
\text { at baseline }\end{array}$ & $69.97 \pm 10.01$ & $69.08 \pm 10.43$ & $69.32 \pm 9.59$ & $73.33 \pm 8.86$ & 0.0031 & 0.83 & 0.0010 & 0.0052 \\
\hline $\begin{array}{l}\text { Maximum \% atheroma area } \\
\text { at follow-up }\end{array}$ & $70.27 \pm 10.46$ & $69.62 \pm 10.72$ & $69.34 \pm 10.23$ & $73.42 \pm 9.54$ & 0.0096 & 0.81 & 0.0047 & 0.0065 \\
\hline \multicolumn{9}{|l|}{ Averaged 2-D IVUS data } \\
\hline $\begin{array}{l}\text { Mean plaque area at } \\
\text { follow-up }\left(\mathrm{mm}^{2}\right)\end{array}$ & $6.74 \pm 2.4$ & $6.56 \pm 2.37$ & $6.56 \pm 2.29$ & $7.46 \pm 2.53$ & 0.024 & 1.00 & 0.0092 & 0.020 \\
\hline $\begin{array}{l}\text { Mean \% atheroma area at } \\
\text { baseline }\end{array}$ & $44.63 \pm 9.68$ & $44.04 \pm 9.56$ & $43.62 \pm 9.85$ & $47.51 \pm 9.37$ & 0.023 & 0.74 & 0.012 & 0.013 \\
\hline $\begin{array}{l}\text { Mean \% atheroma area at } \\
\text { follow-up }\end{array}$ & $45.30 \pm 9.97$ & $44.32 \pm 9.69$ & $44.18 \pm 10.11$ & $49.37 \pm 9.59$ & 0.0008 & 0.91 & 0.0004 & 0.0011 \\
\hline $\begin{array}{l}\text { Change in mean \% atheroma } \\
\text { area }(\%)\end{array}$ & $0.68 \pm 3.40$ & $0.28 \pm 3.32$ & $0.56 \pm 2.96$ & $1.86 \pm 3.90$ & 0.0047 & 0.53 & 0.0012 & 0.017 \\
\hline \multicolumn{9}{|l|}{ 3-D IVUS data } \\
\hline $\begin{array}{l}\text { Atheroma volume at } \\
\text { baseline }(\%)\end{array}$ & $45.33 \pm 9.48$ & $44.56 \pm 9.24$ & $44.67 \pm 9.07$ & $48.41 \pm 10.20$ & 0.0047 & 0.92 & 0.0017 & 0.0061 \\
\hline $\begin{array}{l}\text { Atheroma volume at } \\
\text { follow-up (\%) }\end{array}$ & $46.00 \pm 9.43$ & $45.16 \pm 9.04$ & $45.05 \pm 9.17$ & $49.66 \pm 10.05$ & 0.0005 & 0.92 & 0.0002 & 0.0007 \\
\hline
\end{tabular}

Data are presented as mean $\pm \mathrm{SD}$

2-D IVUS data were available in 426 (most severe lesion) and 332 (averaged measurements) participants, respectively; 3-D IVUS data were available in 419 participants

NG, normoglycaemia

$>6.3 \%$. There were no significant differences among the lower three quartiles; however, each had a significantly lower percentage atheroma volume than the highest quartile.

Table 3 Correlations of baseline FBG and $\mathrm{HbA}_{1 \mathrm{c}}$ with coronary artery dimensions

2-D IVUS data were available in 426 (most severe lesion) and 332 (averaged measurements) participants, respectively; 3-D IVUS data were available in 419 participants



In a multivariate model, $\mathrm{HbA}_{1 \mathrm{c}}$ correlated with plaque burden as measured by baseline atheroma volume $(p=0.025)$, as did female sex $(p=0.032)$, while baseline LDL-cholesterol was of borderline statistical significance $(p=0.079)$. Both

\begin{tabular}{|c|c|c|c|c|}
\hline \multirow[t]{2}{*}{ Variables } & \multicolumn{2}{|l|}{ FBG } & \multicolumn{2}{|l|}{$\mathrm{HbA}_{1 \mathrm{c}}$} \\
\hline & $r$ & $p$ value & $r$ & $p$ value \\
\hline \multicolumn{5}{|l|}{ 2-D IVUS data } \\
\hline Minimum lumen area at baseline $\left(\mathrm{mm}^{2}\right)$ & -0.14 & 0.0026 & -0.19 & 0.0042 \\
\hline Max. plaque area at follow-up $\left(\mathrm{mm}^{2}\right)$ & 0.079 & 0.104 & 0.18 & 0.0079 \\
\hline Maximum \% atheroma area at baseline & 0.17 & 0.0003 & 0.26 & 0.0001 \\
\hline \multicolumn{5}{|l|}{ Averaged 2-D IVUS data } \\
\hline Mean plaque area at follow-up $\left(\mathrm{mm}^{2}\right)$ & 0.12 & 0.030 & 0.15 & 0.040 \\
\hline Mean $\%$ atheroma area at follow-up & 0.11 & 0.041 & 0.21 & 0.0027 \\
\hline \multicolumn{5}{|l|}{ 3-D IVUS data } \\
\hline Plaque volume at baseline $\left(\mathrm{mm}^{3}\right)$ & 0.09 & 0.079 & 0.13 & 0.049 \\
\hline Plaque volume at follow-up $\left(\mathrm{mm}^{3}\right)$ & 0.083 & 0.09 & 0.20 & 0.0033 \\
\hline Lumen volume at baseline $\left(\mathrm{mm}^{3}\right)$ & -0.090 & 0.066 & -0.11 & 0.09 \\
\hline Lumen volume at follow-up $\left(\mathrm{mm}^{3}\right)$ & -0.085 & 0.083 & 0.083 & 0.22 \\
\hline Atheroma volume at baseline $(\%)$ & 0.15 & 0.0020 & 0.24 & 0.0003 \\
\hline Atheroma volume at follow-up (\%) & 0.15 & 0.0016 & 0.27 & $<0.0001$ \\
\hline
\end{tabular}


FBG and glycaemic group correlated by univariate analysis, but not when included in the multivariate model with $\mathrm{HbA}_{1 \mathrm{c}}$.

$\mathrm{HbA}_{1 \mathrm{c}}$ levels were lower in diet-controlled diabetic patients $(6.5 \pm 1.0 \%, n=14, p<0.0001)$ and in diabetic patients treated with oral hypoglycaemic drugs $(6.9 \pm$ $0.9 \%, n=39, p<0.0001)$ than in those treated with insulin $(7.8 \pm 1.1 \%, n=19)$.

\section{Discussion}

The major findings of our study are that: (1) coronary atheroma burden was greater in diabetic patients than in patients with normal glycaemia or IFG; (2) the relationship between atherosclerosis severity and coronary remodelling differed according to glycaemic status; and (3) FBG and $\mathrm{HbA}_{1 \mathrm{c}}$ correlated with plaque burden, atherosclerosis progression and coronary remodelling across all patient groups.

To date, most imaging studies relating glycaemic status to $\mathrm{CAD}$ have lacked information on serial examinations $[2,11,12,19,20]$, diabetes treatment $[3,5,10-12,19]$, FBG $[5,10,11,19,20]$ or a non-diabetic control group $[11,20]$. Our investigation provides more detailed information than these previous reports, helps clarify some of the outstanding questions on this subject and complements the results from a recent pooled analysis of five randomised clinical trials [3]. Our study provides clinically relevant insights into 'early' CAD in diabetic patients compared with normoglycaemic and IFG patients.

Glycaemic status, coronary atheroma burden and coronary remodelling Our study is the first to provide IVUS information on coronary atheroma burden in patients with IFG. We found that atheroma burden and the progression of atheroma burden are increased in diabetes, but not in IFG patients. Atheroma progression is related to continuous measures of glycaemic control, implying that intensive control of diabetes [21] may attenuate the progression of coronary atherosclerosis in diabetes.

We observed that the usual interrelationships between plaque and lumen areas [10] were disturbed in diabetes and that vascular remodelling was thus not active as a protective mechanism across as wide a range of lesion severity as in non-diabetic patients. This failure of vascular remodelling associated with diabetes may be caused by increased extracellular fibrosis [22].

Blood glucose, $H b A_{l_{c}}$ and $C A D$ Consistent with the report from Nicholls et al. [3], we demonstrated that coronary atheroma burden correlates with actual measures of glycaemic control, such as $\mathrm{FBG}$ and $\mathrm{HbA}_{1 \mathrm{c}}$. Poor metabolic control, reflected by elevated $\mathrm{FBG}$ and $\mathrm{HbA}_{1 \mathrm{c}}$, correlates with an increased atheroma burden. $\mathrm{HbA}_{1 \mathrm{c}}$ correlated better with atheroma burden and progression of atherosclerosis over time, probably because it represents a better assessment of glycaemic control over time than a single FBG measurement.

We also demonstrated correlations between $\mathrm{HbA}_{1 \mathrm{c}}$ and vascular remodelling. The correlations between $\mathrm{HbA}_{1 \mathrm{c}}$ and changes in total vessel dimensions over time can probably be explained at least in part by enhanced plaque accumulation due to poor glycaemic control. Our observations extend those of Nicholls et al. [3] and differ from earlier, smaller studies that failed to demonstrate a relationship between $\mathrm{HbA}_{1 \mathrm{c}}$ and remodelling $[11,20]$. In the Reversal of atherosclerosis with aggressive lipid lowering therapy (REVERSAL) trial, a similarly sized trial to our own, diabetes status was not a predictor of coronary artery remodelling, but data on $\mathrm{FBG}$ and $\mathrm{HbA}_{1 \mathrm{c}}$ were lacking [10].

Study limitations Patients with $\mathrm{HbA}_{1 \mathrm{c}}>10 \%$ were not included in this analysis; therefore our findings may under-represent the magnitude of the diabetes-related effects on CAD. We did not have information on fasting insulin concentrations or abdominal girth. Also, we only had one measurement of $\mathrm{FBG}$ and $\mathrm{HbA}_{1 \mathrm{c}}$, and might have found tighter correlations if we had had average measurements over the course of follow-up. In addition, we had no data on postprandial glucose levels or overall glycaemic burden; indeed, patients were classified on the basis of medical history and one measurement of FBG. We were unable to distinguish between type 1 and type 2 diabetes at baseline. However, our patients certainly appeared to be fairly typical of patients with coronary disease and diabetes.

Conclusions Glycaemic status and measures of glycaemic control in a population of non-diabetic and diabetic participants are associated with the severity and progression of coronary atherosclerosis. The relationship between the severity of atherosclerosis and coronary remodelling is also affected by glycaemic status. Our observations support the role of early detection and intervention in IFG and diabetes.

Acknowledgements We gratefully acknowledge the expert work of staff at the intravascular ultrasound core laboratory (J. Vincent, G. Grenier, C. Roy and C. Léger-Gauthier). J.-C. Tardif holds the Pfizer and Canadian Institutes of Health Research Chair in Atherosclerosis. C. Berry was supported by a British Heart Foundation International Fellowship and a Royal Society of Edinburgh International Exchange Programme Award.

Duality of interest The authors declare that there is no duality of interest associated with this manuscript. 


\section{References}

1. Berry C, Tardif JC, Bourassa MG (2007) Coronary heart disease in patients with diabetes - part I: recent advances in prevention and non-invasive management. J Am Coll Cardiol 49:631-642

2. Kornowski R, Mintz GS, Lansky AJ et al (1998) Paradoxic decreases in atherosclerotic plaque mass in insulin-treated patients. Am J Cardiol 81:1298-1304

3. Nicholls SJ, Tuzcu EM, Kalidini S et al (2008) Effect of diabetes on progression of coronary atherosclerosis and arterial remodeling: a pooled analysis of 5 intravascular ultrasound trials. J Am Coll Cardiol 52:255-262

4. von Birgelen C, Hartmann M, Mintz GS et al (2004) Relationship between cardiovascular risk as predicted by established risk scores vs plaque progression as measured by serial intravascular ultrasound in left main coronary arteries. Circulation 110:1579-1585

5. Nicholls SJ, Tuzcu EM, Crowe T et al (2006) Relationship between cardiovascular risk factors and atherosclerotic disease burden measured by intravascular ultrasound. J Am Coll Cardiol 47:1967-1975

6. Gerstein HC, Pogue J, Mann JFE et al (2005) The relationship between dysglycaemia and cardiovascular and renal risk in diabetic and non-diabetic participants in the HOPE study: a prospective epidemiological analysis. Diabetologia 48:1749-1755

7. White CW, Wright CB, Doty DB et al (1984) Does visual interpretation of the coronary angiogram predict the physiologic importance of a coronary stenosis? N Engl J Med 310:819-824

8. De Scheerder I, de Man F, Herregods MC et al (1994) Intravascular ultrasound vs angiography for measurement of luminal diameters in normal and diseased coronary-arteries. Am Heart J 127:243-251

9. Mintz GS, Nissen SE, Anderson WD et al (2001) American College of Cardiology clinical expert consensus document on standards for acquisition, measurement and reporting of intravascular ultrasound studies (IVUS). J Am Coll Cardiol 37:1478-1492

10. Schoenhagen P, Tuzcu EM, Apperson-Hansen C et al (2006) Determinants of arterial wall remodeling during lipid-lowering therapy - serial intravascular ultrasound observations from the Reversal of Atherosclerosis with Aggressive Lipid Lowering Therapy (REVERSAL) trial. Circulation 113:2826-2834

11. Jimenez-Quevedo P, Sabate M, Angiolillo D et al (2005) LDLcholesterol predicts negative coronary artery remodelling in diabetic patients: an intravascular ultrasound study. Eur Heart J $26: 2307-2312$
12. Larsen JB, Tsunoda T, Tuzcu A et al (2007) Intracoronary ultrasound examinations reveal significantly more advanced coronary atherosclerosis in people with type 1 diabetes than in age- and sex-matched non-diabetic controls. Diab Vasc Dis Res 4:62-65

13. Tardif JC, Gregoire J, Lesperance J et al (2002) Design features of the Avasimibe and progression of coronary lesions assessed by intravascular ultrasound (A-PLUS) clinical trial. Am Heart J 144:589-596

14. Tardif JC, Gregoire J, L'Allier PL et al (2004) Effects of the acyl coenzyme A: cholesterol acyltransferase inhibitor avasimibe on human coronary atherosclerotic lesions. Circulation 110:33723388

15. American Diabetes Association (2007) Diagnosis and classification of diabetes mellitus. Diabetes Care 30:S42-S47

16. Tardif JC, Bertrand OF, Mongrain R et al (2000) Reliability of mechanical and phased-array designs for serial intravascular ultrasound examinations - animal and clinical studies in stented and non-stented coronary arteries. Int J Card Imaging 16:365-375

17. Tardif JC, Gregoire J, L'Allier PL et al (2006) Effect of atherosclerotic regression on total luminal size of coronary arteries as determined by intravascular ultrasound. Am J Cardiol 98:23-27

18. Berry C, L'Allier PL, Gregoire J et al (2007) Comparison of intravascular ultrasound and quantitative coronary angiography for the assessment of coronary artery disease progression. Circulation 115:1851-1857

19. Vavuranakis M, Stefanadis C, Toutouzas K, Pitsavos C, Spanos V, Toutouzas P (1997) Impaired compensatory coronary artery enlargement in atherosclerosis contributes to the development of coronary artery stenosis in diabetic patients - an in vivo intravascular ultrasound study. Eur Heart J 18:1090-1094

20. Jensen LO, Thayssen P, Mintz GS et al (2007) Intravascular assessment of remodeling and reference segment plaque burden in type 2 diabetic patients. Eur Heart J 28:1759-1764

21. United Kingdom Prospective Diabetes Study (UKPDS) Group (1998) Intensive blood-glucose control with sulphonylureas or insulin compared with conventional treatment and risk of complications in patients with type 2 diabetes (UKPDS 33). Lancet 352:837-853

22. Sommeijer DW, Beganovic A, Schalkwijk CG et al (2004) More fibrosis and thrombotic complications but similar expression patterns of markers for coagulation and inflammation in symptomatic plaques from DM2 patients. J Histochem Cytochem 52:1141-1149 